\title{
Glicemia e concentrações séricas de insulina, triglicérides e cortisol em equinos da raça Quarto de Milha e mestiços usados em provas de laço em dupla
}

\author{
Glycemy and serum concentrations of insuline, triglycerides and cortisol in Quarter \\ horses and crossbred submitted to team ropping
}

\author{
Larize de Oliveira RAMALHO'; Julio Cesar Costa CAIADO'; ${ }^{1}$ Vinicius Ricardo Cuña de SOUZA²; \\ Clarisse Simões COELHO ${ }^{2}$
}

\author{
${ }^{1}$ Programa de Mestrado em Ciência Animal da Universidade Vila Velha, Vila Velha-ES, Brasil \\ ${ }^{2}$ Professor de Graduação em Medicina Veterinária e do Curso de Mestrado em Ciência Animal da Universidade Vila Velha, \\ Vila Velha-ES, Brasil
}

\begin{abstract}
Resumo
O objetivo do presente estudo foi avaliar a influência de uma prova de laço em dupla, caracterizado por ser um exercício físico de curta duração e alta intensidade, sobre a glicemia e concentrações séricas de cortisol, insulina e triglicérides em equinos, durante competição realizada no estado do Espírito Santo. Para tal, foram obtidas amostras de soro e plasma de dez equinos, da raça Quarto de Milha ou mestiços, em três momentos, assim definidos: no repouso, uma semana antes da prova atlética, já com o animal em treinamento (T0); antes da prova atlética (T1) e imediatamente após o término da mesma (T2). A análise dos resultados demonstrou a não influência do exercício físico imposto sobre a glicose plasmática, com valores plasmáticos de $96,1 \pm 12,9 \mathrm{mg} / \mathrm{dL}, 101,3 \pm 11,9 \mathrm{mg} / \mathrm{dL}$ e $100,2 \pm 13,9 \mathrm{mg} / \mathrm{dL}$, e sobre a insulina sérica, com valores médios de $1,95 \pm 1,47 \mu \mathrm{UI} / \mathrm{mL}, 2,36 \pm 1,21 \mu \mathrm{UI} / \mathrm{mL}$ e $1,54 \pm 1,08 \mu \mathrm{UI} / \mathrm{mL}$, respectivamente, nos tempos T0, T1 e T2. De forma oposta, foi possível observar uma influência significativa sobre triglicérides séricos, com valores médios de $17,9 \pm 4,7 \mathrm{mg} / \mathrm{dL}, 23,7 \pm 11,8 \mathrm{mg} / \mathrm{dL}$ e $42,3 \pm 20,6 \mathrm{mg} / \mathrm{dL}$, e sobre o cortisol sérico, com valores médios de $7,49 \pm 3,46 \mu \mathrm{g} / \mathrm{dL}, 6,86 \pm 2,76 \mu \mathrm{g} / \mathrm{dL}$ e $10,89 \pm 3,99 \mu \mathrm{g} / \mathrm{dL}$, respectivamente nos tempos T0, T1 e T2. A interpretação dos resultados permitiu sugerir que os equinos usados estavam aptos ao nível de atividade física imposta.
\end{abstract}

Palavras-chave: Equinos. Cortisol. Glicose. Insulina. Laço em dupla.

\begin{abstract}
The aim of the present study was to evaluate the effects of a ropping team competition (high intensity and short duration exercise) on glycemy and serum concentrations of cortisol, insuline and triglycerides in horses during competition at Espírito Santo state, Brazil. Blood samples were obtained from 10 Quarter Horses, or cross-bred, in three moments: (1) at rest, one week before the competition, with the animals being trained, (2) just before the competition, and (3) immediately after the exercise. Results showed that the imposed exercise did not influence plasmatic glucose, with mean values of $96.1 \pm 12.9 \mathrm{mg} / \mathrm{dL}, 101.3 \pm 11.9 \mathrm{mg} / \mathrm{dL}$ e $100.2 \pm 13.9 \mathrm{mg} / \mathrm{dL}$, and serum insuline, with mean values of $1.95 \pm 1.47 \mu \mathrm{UI} / \mathrm{mL}, 2.36 \pm 1.21 \mu \mathrm{UI} / \mathrm{mL}$ e $1.54 \pm 1.08 \mu \mathrm{UI} / \mathrm{mL}$, respectively on the moments $\mathrm{T} 0$, T1 and T2. Differently, it was possible to observe a positive influence of the exercise over serum triglycerides, with mean values of $17.9 \pm 4.7 \mathrm{mg} /$ $\mathrm{dL}, 23.7 \pm 11.8 \mathrm{mg} / \mathrm{dL}$ e $42.3 \pm 20.6 \mathrm{mg} / \mathrm{dL}$, and serum cortisol, with mean values of $7.49 \pm 3.46 \mu \mathrm{g} / \mathrm{dL}, 6.86 \pm 2.76 \mu \mathrm{g} / \mathrm{dL}$ e $10.89 \pm 3.99 \mu \mathrm{g} / \mathrm{dL}$, respectively on the moments T0, T1 and T2. It was possible to suggest that horses were adapted to the imposed level of exercise.
\end{abstract}

Keywords: Equine. Cortisol. Glucose. Insuline. Team ropping.

\section{Introdução}

O sistema endócrino tem importante participação em humanos e animais submetidos ao exercício físico realizado durante treinamentos ou competições ${ }^{1}$. Segundo Hyyppä2 o exercício físico desencadeia a liberação de diversos hormônios, dentre os quais catecolaminas e cortisol. A liberação do cortisol ocorre em
Correspondência para:

Clarisse Simões Coelho

Universidade Vila Velha (UVV-ES)

Rua Comissário José Dantas de Melo, 21, Vila Velha

CEP.: 29102-770

e-mail: clarisse.coelho@uvv.br

Recebido: 21/10/2011

Aprovado: 15/08/2012 
resposta a elevação de ACTH, com pico circulatório ocorrendo de cinco a 30 minutos após o término do exercício ${ }^{3}$. Sua principal função é prover a biodisponibilidade dos precursores energéticos necessários para manter os esforços musculares através de diversas vias de ação, dentre as quais degradação de proteínas teciduais para liberação de aminoácidos usados na gliconeogênese hepática, mobilização de ácidos graxos livres do tecido adiposo e redução da taxa de utilização celular de glicose ${ }^{2}$.

Portanto, já é esperado um aumento nas concentrações séricas de cortisol durante as provas equestres ${ }^{1,4}$, porém, esta resposta varia conforme a intensidade e duração do exercício, nível de condicionamento atlético, estado nutricional e, até mesmo, ritmo circadiano, sendo que seu aumento já foi correlacionado tanto com exercício de alta intensidade quanto com exercício físico constante e moderado por tempo prolongado ${ }^{5,6}$. Este aumento de cortisol no pós-exercício estaria mais relacionado com a duração do mesmo, podendo os valores atingir o dobro do registrado no repouso ${ }^{7}$. Segundo Islas et al. ${ }^{6}$, os valores pós-prova são sempre superiores aos encontrados no repouso.

Diversos autores ${ }^{1,6,7,8}$ relatam que a mensuração de cortisol sérico poderia ser usada como índice de avaliação de treinamento, pois sua liberação é menor em indivíduos treinados quando comparados aos não treinados quando submetidos ao mesmo tipo de exercício durante o mesmo tempo. No repouso, Marc et al. ${ }^{8}$ citam intervalo de valores entre 1,47 e 6,73 $\mu \mathrm{g} /$ dL e Dugat et al. ${ }^{9}$ citam valores oscilando entre 2,9 e $6,6 \mu \mathrm{g} / \mathrm{dL}$. Coelho et al. ${ }^{10}$ descreveram valores oscilando entre 7,46 e 12,45 $\mu \mathrm{g} / \mathrm{dL}$ nos equinos da raça Mangalarga Marchador usados em sua pesquisa.

Como consequência das catecolaminas circulantes frente ao exercício físico e concomitante a ação do cortisol, há a redução na liberação de insulina e o aumento de glucagon circulante ${ }^{2,11}$, promovendo um efeito hiperglicemiante. $\mathrm{O}$ aumento da glicemia frente ao exercício já foi descrito ${ }^{3,7} \mathrm{em}$ equinos submetidos a diferentes in- tensidades de atividade física. Martins et al. ${ }^{12}$ citaram valores de glicemia em cavalos da raça Árabe no repouso de $86,9 \mathrm{mg} / \mathrm{dL}$ atingindo $116,3 \mathrm{mg} / \mathrm{dL} 30$ minutos após o exercício. Gordon et al. ${ }^{3}$ citaram como valores de referência no jejum o intervalo entre $80-95 \mathrm{mg} / \mathrm{dL}$. Nadeau et al. ${ }^{13}$ registraram o intervalo de $59,8-82,0 \mathrm{mg} / \mathrm{dL}$ para equinos da raça Morgan e de 66,6-87,6mg/dL para equinos da raça Puro Sangue Inglês.

De forma adicional, além do aumento da glicemia, ocorre uma redução concomitante dos valores séricos de insulina ${ }^{14,15}$. Dugat et al. ${ }^{9}$ citaram valores de referência de insulina para equinos no repouso entre 4,9 $\mu \mathrm{UI} / \mathrm{mL}$ e $45,5 \mu \mathrm{UI} / \mathrm{mL}$. Nadeau et al. ${ }^{13}$ registraram valores de insulina de $2,7-8,2 \mu \mathrm{UI} / \mathrm{mL}$ para equinos da raça Morgan e de 2,3-12,0 $\mu \mathrm{UI} / \mathrm{mL}$ para equinos da raça Puro Sangue Inglês. McGowan ${ }^{16}$ citou que valores inferiores a $62 \mu \mathrm{UI} / \mathrm{mL}$ são considerados normais quanto a insulinemia. Ralston ${ }^{17}$ citou valores de referência para insulina entre $<5 \mu \mathrm{UI} / \mathrm{mL}$ a $20 \mu \mathrm{UI} / \mathrm{mL}$.

A ação de catecolaminas e cortisol gera um equilíbrio energético negativo semelhante ao provocado pelo jejum alimentar, com aumento da lipólise e do catabolismo de proteínas corporais ${ }^{18}$. Segundo Dugat et al. ${ }^{9}$, os valores séricos de triglicérides no repouso atingem $33,82 \mathrm{mg} / \mathrm{dL}$ e no jejum chegam a $112,74 \mathrm{mg} /$ dL. Apesar dos poucos estudos envolvendo o metabolismo lipídico frente ao exercício, acredita-se que a resposta observada seja semelhante. Orozco et al. ${ }^{15}$ observaram aumento gradativo nos valores de triglicérides séricos com o aumento do esforço físico dos equinos de enduro avaliados em seu experimento (de $34,9 \mathrm{mg} / \mathrm{dL}$ no momento antes a $58,5 \mathrm{mg} / \mathrm{dL}$ no momento de desaceleração). Segundo os referidos autores, isto pode ser explicado devido ao maior requerimento de energia frente ao exercício e provavelmente porque se inicia um processo oxidativo de ácidos graxos no músculo esquelético, os quais atuam como precursores dos triglicérides. Durante a recuperação do exercício, as concentrações plasmáticas de triglicérides caem consideravelmente, conforme 
a de insulina aumenta em consequência do retorno alimentar ${ }^{2}$. Nadeau et al. ${ }^{13}$ registraram valores de triglicérides séricos de 11,1-31,6mg/dL para equinos da raça Morgan e de 7,4-25,8mg/dL para equinos da raça Puro Sangue Inglês.

A compreensão de tais mecanismos fisiológicos e sua caracterização são de enorme importância na avaliação da performance de equinos atletas ${ }^{19}$. Além disto, existem poucos relatos envolvendo equinos usados em provas western, como as provas de laço em dupla, treinados em condições climáticas tropicais ${ }^{12}$. Sendo assim, o objetivo do presente trabalho foi avaliar a influência do exercício físico caracterizado pela prova de laço em dupla sobre a glicemia e concentrações séricas de cortisol, insulina e triglicérides em equinos da raça Quarto de Milha e de mestiços, durante competição realizada no estado do Espírito Santo.

\section{Material e Método}

Foram utilizados dez equinos da raça Quarto de Milha, ou mestiços da referida raça, todos machos, pesando em média $500 \mathrm{~kg}$, com idade variando entre cinco e 14 anos (média de $9 \pm 4$ anos de idade), considerados clinicamente hígidos, mediante exame físico e exames laboratoriais, incluindo hemograma. Estes animais pertencem a criatórios localizados na região da Grande Vitória, estado do Espírito Santo. Os animais usados foram submetidos ao mesmo tipo de manejo alimentar e sanitário. Além disso, todos os equinos selecionados encontravam-se no mesmo estágio de treinamento (três a quatro vezes na semana são aquecidos e treinados no ritmo da prova e, nos demais dias, são submetidos a galopes - treinos com duração média de duas horas) e executavam tal atividade há pelo menos dois anos. O treinamento só foi interrompido 24 horas antes da prova para o transporte dos animais até o local da competição.

A prova de laço em dupla, também conhecida por team ropping, é uma prova em que uma dupla de cavaleiros laça um bezerro, sendo um dos cavaleiros responsável por laçar a cabeça e o outro responsável por laçar os pés. O tempo da prova, em média de oito a dez segundos, abrange desde o momento em que os cavaleiros saem do boxe até laçarem o bezerro, mantendo-o sobre a corda esticada e amarrada à sela do cavalo. Tal atividade física caracteriza um exercício de alta intensidade e curta duração.

As amostras de sangue foram obtidas após antissepsia local, por meio de venopunção da jugular com agulhas descartáveis $(25,0 \times 0,8 \mathrm{~mm})$, utilizando-se sistema a vácuo, em tubos de vidro contendo anticoagulante EDTA-fluoreto de sódio com capacidade de $2 \mathrm{~mL}$, para avaliação plasmática de glicose; e em tubos de vidro siliconizados sem anticoagulante com capacidade de $9 \mathrm{~mL}$, para as determinações séricas de cortisol, insulina e triglicérides. As coletas foram feitas em três momentos para cada equino estudado, sendo assim caracterizadas: momento repouso - T0 (obtida uma semana antes da prova atlética, com o animal em repouso, mas dentro do período de treinamento, no horário entre 8h:00 e 10h:00 da manhã), momento pré-prova - T1 (obtida antes da prova atlética) e momento pós-prova - T2 (obtida num período de até no máximo cinco minutos após a realização da atividade física). Para todos os animais usados, a amostra de sangue pós-prova foi coletada após a realização da primeira bateria completa de atividade, ou seja, quando os animais completavam o percurso, de forma a padronizar as coletas e avaliações. No dia da prova de laço, foram registradas as características da pista e condições climáticas.

Todas as amostras foram transportadas sob refrigeração ao Laboratório Clínico Veterinário da Universidade Vila Velha (UVV-ES) para processamento. As amostras obtidas em frascos sem anticoagulante e com anticoagulante EDTA-fluoreto de sódio foram imediatamente centrifugadas durante dez minutos (Centrífuga modelo TDL80-2B, Centribio, China) a $4000 \mathrm{rpm}$ para separação de, respectivamente, soro e plasma. 
Para determinação sérica de cortisol e insulina, foi utilizada a técnica de radioimunoensaio em fase sólida usando kits comerciais (Siemens Healthcare Diagnostics Inc., Tarrytown, NY, USA), conforme especificações do fabricante. Todos os testes foram realizados em duplicata e previamente validados para uso em equinos, de acordo com metodologia descrita por Freestone et al. ${ }^{14}$. Tais determinações foram realizadas no BET Laboratórios (Rio de Janeiro, RJ). O encaminhamento para as análises foi feito imediatamente após a obtenção do soro.

A glicose plasmática foi determinada através de metodologia enzimática ${ }^{20}$, utilizando kit comercial (Glicose K054, Bioclin, Belo Horizonte - MG, Brasil), em comprimento de onda de $510 \mathrm{~nm}$, e a determinação sérica de triglicérides foi feita através de método enzimático colorimétrico ${ }^{21}$, usando kit comercial (Triglicérides Liquido Estável K055, Bioclin, Belo Horizonte - MG, Brasil), em comprimento de onda de 540 $\mathrm{nm}$, ambos em aparelho analisador semiautomático (BIO200, Bioplus, São Paulo - SP, Brasil). Ambas as análises também foram processadas imediatamente após a obtenção de plasma/soro.

A análise dos resultados - glicose plasmática e cortisol, insulina e triglicérides séricos - foi realizada utilizando-se o programa estatístico computadorizado GraphPad InStat (versão 3.0). Devido à distribuição gaussiana dos dados, os mesmos foram avaliados através de testes paramétricos (análise de variância - ANOVA e teste de Tukey) para comparação entre médias com nível de significância de 5\%.

\section{Resultados}

O exame físico e os exames laboratoriais realizados para seleção dos equinos usados na presente pesquisa demonstraram que todos os animais apresentavam frequência cardíaca média de 41 bpm, frequência respiratória média de $18 \mathrm{mpm}$, motilidade intestinal presente à auscultação, mucosas róseas e temperatura retal de $37,8^{\circ} \mathrm{C}$. Os valores do hemograma encontravam-se dentro da normalidade para a espécie segundo Robinson ${ }^{22}$.

No momento da prova, a pista de areia encontrava-se seca. A temperatura média local era de $29^{\circ} \mathrm{C} \mathrm{e}$ umidade relativa do ar de $80 \%$, características climáticas locais típicas de climas tropicais (quente e úmido).

$\mathrm{Na}$ tabela 1 estão apresentados os valores médios e desvios-padrão para os valores plasmáticos de glicose e valores séricos de cortisol, insulina e triglicérides séricos, além dos valores de $p$ obtidos na análise de variância (ANOVA). Na avaliação dos resultados obtidos, foi possível observar que o exercício físico imposto influenciou de forma significativa as concentrações séricas de cortisol $(\mathrm{p}=0,0308)$, bem como de triglicérides $(\mathrm{p}=0,0015)$. Não houve influência do tipo de exercício imposto sobre a glicose plasmática

Tabela 1 - Valores médios e desvios-padrão das concentrações séricas de cortisol, insulina e triglicérides e concentrações plasmáticas de glicose nos equinos da raça Quarto de Milha usados em prova de laço em dupla nos momentos T0, T1 e T2. Vila Velha - ES

\begin{tabular}{ccccc}
\hline & T0 & T1 & T2 & $P$ \\
\hline Cortisol $(\boldsymbol{\mu g} / \mathbf{d L})$ & $7,49 \pm 3,46^{\mathrm{ab} *}$ & $6,86 \pm 2,76^{\mathrm{a}}$ & $10,89 \pm 3,99^{\mathrm{b}}$ & 0,0308 \\
Insulina $(\boldsymbol{\mu U I} / \mathbf{m L})$ & $1,95 \pm 1,47^{\mathrm{a}}$ & $2,36 \pm 1,21^{\mathrm{a}}$ & $1,54 \pm 1,08^{\mathrm{a}}$ & 0,3629 \\
Glicose $(\mathbf{m g} / \mathbf{d L})$ & $96,1 \pm 12,9^{\mathrm{a}}$ & $101,3 \pm 11,9^{\mathrm{a}}$ & $100,2 \pm 13,9^{\mathrm{a}}$ & 0,6426 \\
Triglicérides $(\mathbf{m g} / \mathbf{d L})$ & $17,9 \pm 4,7^{\mathrm{a}}$ & $23,7 \pm 11,8^{\mathrm{a}}$ & $42,3 \pm 20,6^{\mathrm{b}}$ & 0,0015 \\
\hline
\end{tabular}

* Letras minúsculas diferentes na mesma linha denotam diferença estatística significativa entre as médias $(p<0,05)$ obtida pelo teste ANOVA. T0 (obtida uma semana antes da prova atlética, com o animal em repouso, mas dentro do período de treinamento, no horário entre 8h:00 e 10h:00 da manhã), momento pré-prova - T1 (obtida antes da prova atlética) e momento pós-prova - T2 (obtida num período de até no máximo cinco minutos após a realização da atividade física 
$(\mathrm{p}=0,6426)$ e insulina sérica $(\mathrm{p}=0,3629)$ ao longo do período experimental.

\section{Discussão}

Por se tratar de um estudo envolvendo avaliação hormonal e sabendo do ritmo circadiano da liberação de cortisol, a presente pesquisa foi realizada no período da manhã, que coincide com o pico de liberação de cortisol $^{6}$; esse procedimento evitou grandes oscilações dos valores estudados e uma interpretação mais fidedigna da influência do exercício físico imposto sobre as concentrações séricas do referido hormônio.

Os valores registrados para o cortisol sérico, na presente pesquisa, em todos os momentos de avaliação, foram superiores aos de referência citados por Marc et al. ${ }^{8}$ e Dugat et al. ${ }^{9}$. Os maiores valores foram registrados na amostra obtida imediatamente após o exercício, semelhante às descrições de Gordon et al. ${ }^{3}$, Islas et al. ${ }^{6}$ e Coelho et al. ${ }^{10}$, que destacaram que o pico de cortisol ocorre entre cinco e 30 minutos após o término da atividade física.

O aumento do cortisol sérico frente a um exercício físico é esperado, pois desencadeia uma cascata de eventos fisiológicos visando a produção eficiente de energia para manutenção dos esforços musculares ${ }^{1}$. Tal aumento frente a uma atividade física também foi constatado neste estudo, onde foi possível observar uma elevação significativa dos valores registrados no momento T1 para T2. De forma semelhante, Orozco et al. ${ }^{15}$, em trabalho nacional usando equinos da raça Árabe exercitados em esteira ergométrica, registraram aumento significativo com valores de $7,24 \mu \mathrm{g} / \mathrm{dL}$ no momento antes e $8,19 \mu \mathrm{g} / \mathrm{dL}$ no momento da suspensão do exercício, valores inferiores no pós-exercício, quando comparados aos registrados nos equinos da raça Quarto de Milha estudados. Essa diferença nos valores provavelmente deve-se ao fato de que o exercício físico imposto nos animais da presente pesquisa representa um exercício de intensidade superior àquela executada pelos animais na pesquisa de Orozco et al. ${ }^{15}$, além de possíveis variações climáticas e condições de pista.

O treinamento físico tende a reduzir a magnitude de elevação do cortisol após provas e/ou exercícios ${ }^{8}$, o que permite que sua mensuração possa ser usada como ferramenta na avaliação do treinamento imposto $^{7}$. Para tanto, são necessárias ao menos duas avaliações físicas entre um período determinado de treino para verificar se este foi eficiente. Apesar disto não ter sido feito na presente pesquisa, os resultados demonstraram a importância do uso desta ferramenta na avaliação do condicionamento atlético frente a um único desafio, associando sempre tais resultados com a avaliação clínica dos animais.

A resposta frente ao estresse, caracterizada por alterações comportamentais, no exame físico (por exemplo, aumento das frequências cardíaca e respiratória) e em exames laboratoriais (por exemplo, elevação nas concentrações de cortisol sérico), representa uma tentativa do organismo de restabelecer a homeostasia após lesão, execução de atividade física e/ou agressão psicológica $^{23}$. Não foi observada diferença significativa nos valores séricos de cortisol registrados entre os momentos T0 e T1, bem como alterações comportamentais e no exame físico, sugerindo que o transporte até o local da prova e a mudança de ambiente não gerou estresse aos animais usados na presente pesquisa que pudesse comprometer a performance dos mesmos.

O efeito hiperglicemiante foi constatado por Gordon et al. ${ }^{3}$, Ferraz et al. ${ }^{7}$ e Martins et al. ${ }^{12}$. Entretanto, na presente pesquisa, essa hiperglicemia pós-exercício não foi observada. Os valores registrados encontram-se dentro dos limites superiores do intervalo de referência descrito por Robinson ${ }^{22}$ para a espécie equina $(75,0-115,0 \mathrm{mg} / \mathrm{dL})$, porém superiores aos valores de referência citados por Nadeau et al. ${ }^{13}$. Mesmo não caracterizando a hiperglicemia pós-exercício descrita por diversos autores supracitados, tais resultados 
sugerem a não utilização de glicose plasmática pelos tecidos visto que não houve declínio de seus valores, priorizando seu uso pelo Sistema Nervoso Central (SNC), evitando a fadiga central ${ }^{7}$.

Os valores séricos registrados para a insulina não apresentaram alteração significativa em nenhum dos momentos estudados, sugerindo a não influência do tipo de exercício físico imposto, sobre esta variável sanguínea, semelhante ao relatado por Hyyppä ${ }^{2}$ e Gordon et al. ${ }^{3}$ e do observado para a glicemia. Tais autores reforçam uma maior influência alimentar, com as elevações séricas deste hormônio ocorrendo quando os equinos voltam a receber alimentos, fato também comprovado por Coelho et al. ${ }^{10}$. A literatura descreve um intervalo bem variado de valores para a insulinemia em equinos e sua interpretação, portanto, deve ser feita com cautela. Os valores registrados na presente pesquisa são inferiores às descrições de Dugat et al. ${ }^{9}$ e Nadeau et al. ${ }^{13}$, porém dentro do intervalo de referência proposto por McGowan ${ }^{16}$ e Ralston ${ }^{17}$.

É esperado um aumento de triglicérides séricos em consequência do balanço energético negativo, semelhante ao que ocorre quando um equino é submetido a jejum alimentar, havendo lipólise e mobilização de outras fontes energéticas ${ }^{9,18}$. Corroborando esses da-

\section{Referências}

1. MIRCEAN, M.; GIURGIU, G.; MIRCEAN, V.; ZINVELIU, E. Serum cortisol variation of sport horses in relation with the level of training and effort intensity. Bulletin USAMV-CN, v. 64 , n. 1-2, p. 488-492, 2007.

2.HYYPPÄ, S. Endocrinal responses in exercising horses. Livestock Product Science, v. 92, p. 113-121, 2005.

3. GORDON, M. E.; MCKEEVER, K. H.; BETROS, C. L.; MANSO FILHO, H. C. Exercise-induced alterations in plasma concentrations of ghrelin, adiponectin, leptin, glucose, insulin and cortisol in horses. The Veterinary Journal, v. 173, n. 3, p. 532-540, 2007.

4. KRAEMER, R. R.; ABOUDEHEN, K. S.; CARRUTH, A. K.; DURAND, R. T.; ACEVEDO, E. O.; JOHNSON, L. G.; CASTRACANE, V. D. Adiponectin responses to continuous and progressively intense intermittent exercise. Medicine and Science in Sport and Exercise, v. 35, n. 8, p. 1320-1325, 2003.

5. McARDLE, W. D.; KATCH, F. I.; KATCH, V. L. Fisiologia do exercício. Rio de Janeiro: Guanabara-Koogan, 1998. 1175 p.

6.ISLAS, A.; MERINO, V.; MORA, G.; QUEZADA, M.; dos, foi constatado aumento significativo na presente pesquisa no momento $\mathrm{T} 2$, com os valores registrados encontrando-se dentro da faixa de normalidade para a espécie equina descrita por Robinson ${ }^{22}$, que cita intervalo de 5,3 a 54,0mg/dL. Este aumento significativo também foi registrado por Orozco et al. ${ }^{15}$, porém, estes autores descreveram valores ligeiramente superiores $(34,0 \mathrm{mg} / \mathrm{dL}$ no momento antes e $58,5 \mathrm{mg} / \mathrm{dL}$ no momento após com os equinos em desaceleração) aos citados na presente pesquisa.

\section{Conclusões}

Os resultados do presente estudo nos permitiram concluir que o tipo de exercício imposto, caracterizado como exercício de curta duração e alta intensidade, levou ao aumento significativo dos valores de cortisol e triglicérides sérico, porém, não houve influência sobre os valores da glicose plasmática e insulina sérica.

Adicionalmente, foi possível sugerir que os equinos estavam aptos à prova física aos quais foram submetidos, pois os resultados encontravam-se dentro de valores fisiológicos pré e pós-exercício, além de clinicamente demonstrarem aptidão para prosseguir para as baterias seguintes da competição.

KRAUSHAAR, R.; ALVAREZ, J.; ARAYA, H. Evaluacion de estres en equinos en entrenamiento para participar em prueba de resistencia. Agro e Ciência, v. 23, n. 2, p. 73-78, 2007.

7. FERRAZ, G. C.; TEIXEIRA-NETO, A. R.; PEREIRA, M. C.; LINARDI, R. L.; LACERDA-NETO, J. C.; QUEIROZ-NETO, A. Influência do treinamento aeróbico sobre o cortisol e glicose plasmaticos em equinos. Arquivo Brasileiro de Medicina Veterinária e Zootecnia, v. 62, n. 1, p. 23-29, 2010.

8. MARC, M.; PARVIZI, N.; ELLENDORFT, F.; KALLWEIT, E.; ELSAESSER, F. Plasma cortisol and ACTH concentrations in the warmblood horse in response to a standardized treadmill exercise test as physiological markers for evaluation of training status. Journal of Animal Science, v. 78, n. 7, p. 1936-1946, 2000 .

9.DUGAT, S. L.; TAYLOR, T. S.; MATHEWS, N.; GOLD, J. R. Values for triglycerides, insulin, cortisol and ACTH in a herd of normal donkeys. Journal Equine Veterinary Science, v. 30, n. 3, p. 141-144, 2011.

10. COELHO, C. S.; GAMA, J. A. N.; LOPES, P. F. R.; SOUZA, V. R. C. Glicemia e concentrações séricas de insulina, triglicérides 
e cortisol em equinos da raça Mangalarga Marchador após exercício físico. Pesquisa Veterinária Brasileira, v. 31, n. 9, p. 756-760, 2011.

11. McKEEVER, K. H. The endocrine system and the challenge of exercise. Veterinary Clinics of North America: Equine Practice, v. 18, n. 2, p. 321-353, 2002.

12. MARTINS, C. B.; OROZCO, C. A. G.; D'ANGELIS, F. H. F.; FREITAS, E. V. V.; CHRISTOVÃO, F. G.; QUEIROZ NETO, A.; LACERDA NETO, J. C. de. Determinação de variáveis bioquímicas em equinos antes e após a participação em provas de enduro. Revista Brasileira de Ciência Veterinária, v. 12 , n. 1/3, p. $62-65,2005$.

13. NADEAU, J. A.; FRANK, N.; VALIPE, S. R.; ELLIOT, S. B. Blood lipid, glucose, and insulin concentrations in Morgan horses and Thoroughbreds. Journal of Equine Veterinary Science, v. 26, n. 9, p. 401-405, 2006.

14. FREESTONE, J. F.; WOLFSHEIMER, K. J.; KAMERLING, S. G.; CHURCH, G.; HAMRA, J.; BAGWELL, C. Exercise induced hormonal and metabolic changes in Thoroughbred horses: effects of conditioning and acepromazine. Equine Veterinary Journal, v. 23, n. 3, p. 219-223, 1991.

15. OROZCO, C. A. G.; MARTINS, C. B.; COMIDE, L. M. W.; QUEIROZ NETO, A. de; LACERDA NETO, J. C. de. Alteraciones metabólicas durante entrenamiento en equinos de la Raza Pura Sangre Árabe. Revista de Medicina Veterinária, n. 13, p. 77-82, 2007.
16. McGOWAN, C. The role of insulin in endocrinopathic laminitis. Journal of Equine Veterinary Science, v. 28, n. 10, p. 603-607, 2008.

17. RALSTON, S. L. Insulin and glucose regulation. Veterinary Clinics of North America: Equine Practice, v. 18, n. 2, p. 295-304, 2002.

18. DURHAM, A. E. Clinical application of parenteral nutrition in the treatment of five ponies and one donkey with hyperlipaemia. Veterinary Record, v. 158, p. 159-164, 2006.

19. MARQUES, M. S. Influência do exercício físico sobre os níveis de lactato plasmático e cortisol sérico em cavalos de corrida. 2002. 70 p. Dissertação (Mestrado) - Faculdade de Medicina Veterinária e Zootecnia, Universidade de São Paulo, São Paulo, 2002.

20. SCHMID, M.; FORSTNER, L. A. Laboratory testing in veterinary medicine diagnosis in the clinical monitoring. Mannheim: Boehringer, 1986. 253 p.

21. BERGMEYER, H. U. Methods of enzymatic analysis. New York: Academic Press, 1974. 1064 p.

22. ROBINSON, E. N. Current therapy in equine medicine. Philadelphia: W.B. Saunders, 2003. 960 p.

23. WAGNER, A. E. Effects of stress on pain in horses and incorporating pain scales for equine practice. Veterinary Clinics: Equine Practice, v. 26, n. 3, p. 481-492, 2010. 